drag in all stages of the disease to see how much patients could take without ill effect and what good results, if any, would follow. In many cases after starting the treatment one has been obliged to cease the administration of the drug as other symptoms or complications (not connected with the guaiacol) have arisen necessitating its withdrawal. We have nevertheless 40 patients who have taken the drug: 6 cases took 60 minims, 2 cases took 50 minims, 4 cases took 40 minims, 6 cases took 30 minim $\%, 10$ cases took 20 minims, 6 cases took 15 minims, and 6 cases took 10 minims three times a day after food. Some of these are still in hospital and are gradually increasing the dose. The drug was first administered in capsules, each containing 0 minims, but later was given in an emulsion with glycerine and tincture of orange peel, many patients taking it partly in one form and partly the other. A good few found difficulty in swallowing many capsules; others, again, preferred them much to the acrid liquid; in either case they would drink about half a cupful of milk with the guaiacol, which seemed to greatly add to its being borne well. The dose of 5 minims was at first usually increased by 5 minims every third day, and later more rapidly, till 60 minims were reached. Only one patient felt any ill effects; he, when taking 20 minims three times a day, complained of much stomachic and abdominal pain with a sinking sensation in the epigastrium, passing a small quantity of blood by the bowel. The guaiacol was stopped, but resumed later with 10-minim doses withont ill effect. 26 were cavitation cases and in these the diminution in the amount of expectoration was very marked, beginning to diminish early in the administration of the drug. Some patients whose expestoration was very profuse on admission would later only cough up little "pellets" of sputum first thing in the morning and none after. There bas been no marked effect on the tempsrature observed when guaiacol has superseded other drugs, but in those taking it continually a steady lowering of the evening temperature bas been commonly noticed. 35 of the cases put on weight, most of them well, one putting on $19 \mathrm{lb}$, in twelve weeks. There was not, as far as I could make out, any definite relation between the increase in weight and the proportional increase of the doses. The cough was in no special way affected that I could see, but night sweats in nearly all cases diminished and then disappeared in a very short space of time. 12 cases had laryngeal phthisis as well, but as these cases all had local treatment also one cannot say whether the guaiacol had any special effect or no. The patients complained a good deal either of the emulsion burning their throat or of their difficulty in swallowing the capsules, but by dint of perseverance combined with faith in the drug they managed very well after a time. The effect of the drug, if any, on the number, \&c , of the bacilli in the sputum is now being observed.

The following is an abstract of the case referred to in the former part of this paper. The patient was a man aged twenty - four years. He was admitted to hospital on Nov. 18th, 1897, complaining of much weakness, sickness, and cough. The patient had been working harder than usual of late and had got run down. The first symptom was hæmoptysis (one pint) six weeks before admission. Congh with weakness and wasting gradually supervened. On admission he was found to be a cachectic pale man. He was $5 \mathrm{ft} .4 \frac{1}{4}$ in. in height and weighed $8 \mathrm{st} .13 \mathrm{lb} .6 \mathrm{oz}$. He had very profuse night sweats and much sickness; the congh was not very troublesome; he had muco-purulent expectoration. With regard to physical signs, there was very slight impairment of the percussion note at the left apex, with a few sharp "clicks" at the end of inspiration. He had continuous temperature of about $102.4^{\circ} \mathrm{F}$. He was treated with an acid tonic and complete rest in bed. On Nov. 22nd the acid was omitted; quinine and digitalis were given. On the 25 th the temperature was gradually falling. He was still sweating much at night. On Dec. 5th the temperature had been remittent, but was continuously high again and was going up. The patient was sick a good deal. Large râles were now heard in the second, third, and fourth spaces in the left front and down the left back commencing from the apex of the lower lobe. On the 10th 2 minims of guaiacol three times a day after food were ordered. He had gradually lost weight up to now. He was ont of bed for an hour and could hardly stand. On Jan. 3rd, 1898, the patient was taking 15 minims of guaiacol three times a day. Fine râles were heard in the left front with some crepitations below. There were a few crepitations at the base in front. Râles heard at the back were much smaller. The temperature kept about $99^{\circ}$. He had put on $8 \mathrm{lb}$. in weight since getting up (Dec. 10 hh). On the 31 st the râles were gradually drying up. He was taking 35 minims of guaiacol three times a day. He had pat on 1 st. in weight. His temperature was normal. He complained of nothing except cough and expectoration the first thing in the morning. From Feb. 15th to 17th there was pain in the left base, friction was heard, and the chest was strapped. 1 drachm of guaiacol three times a day, all in capsules, was given with no ill-effects. His temperature was normal. He was 1 st. $5 \mathrm{lb}$. heavier than on Dec. 10th. On March 7th the patient went out. He expressed himself as perfectly well and strong. He had taken 1 drachm of guaiacol thrice daily up to now. He had gained $22 \mathrm{lb}$. in weight since Dec. 10th, when he commenced guaiacol. There were no tubercle bacilli in the sputa when he left the hospital.

Harley-street, W.

\section{A THEORY OF NERVOUS CONDUCTION.}

By W. S. HEDLEY, M.D. EdIN., M.R.C.S. ENG.

IN 1889 it was observed by Professor Oliver Lodge that two knobs sufficiently close together could, when a spar passed between them, actually cohere and, with a single voltaic cell in circuit, conduct "an ordinary bell-ringing current." Shortly afterwards M. Edouard Branly ${ }^{1}$ found that a tube of metallic filings enormously diminished its resistance when exposed to the neighbourhood of a Leyden jar or coil sparks. An arrangement of this kind proved to be a sensitive detector of radiation and such discontinuous conductors came to be called "coherers." The cohesion brought about by electrical means could be broken down by mechanical means. Thus sound-vibration or slight taps would restore the contact to its original condition of high resistance.

In a paper presented to the Académie des Sclences on Dec. 27th last M. Branly suggests certain points of possible resemblance between coherer action and the conductivity of the nerves for nervous impulses. He points out that in reality there is no very clear line of demarcation between continuous and discontinuous conductors; it is rather a question of degree. Passing from artificial to "natural" conductors he argues that the use of the term "nervous current" since the earliest days of physiological research seems to point to some recognised resemblance between nervous and electrical conduction. Until recently it was thought that the various elements of the nervous system were continuous. Now, since the advent of that trinity in unity known as the neurone the nerrous system may be regarded as composed of discontinuous elementsi.e., of elements contiguous but not continuous. It thus becomes possible to regard the neurone as the counterpart of the metallic granule of certain discontinuous conductors. As a blow rill weaken and eren abolish the conducting power in the latter, so traumatism may produce anæsthesia and hysterical paralysis-the latter due to a suppression of transmission, sensory or motor, of the nervous influence consequent on a defective contiguity of nerve elements. Again, as the oscillation of electrical discharges establishes the conductivity of discontinous conductors, so it is known that such discharges act efficiently in the cure of paralysis and hysterical anæsthesia. The possibility, therefore, sug gests itself that in both cases the effect is determined by bringing about the contignity of the elements of the conductor or some modification equivalent to contiguity. The parallelism between the action of a blow and of sparks upon discontinuous conductors and upon the hysterical nervous system may be carried further in the susceptibility common to both of reacting under a feeble stimulus when once a powerfal action is produced as a first effect-a condition which M. Branly has referred to in a former note to the Academy as " sensibilisation par un premier effet" (Dec. 6th, 1897). The high frequency discharges and the electric oscillations which accompany them are especially apt to make discontinuous conductors conduct, and it is such discharges that have been shown by d'Arsonval to have 
Gerapeatic effects in diseases due to perverted nutrition. If the latter affections are of nerrous origin and are due to imperfect transmission of the nervous influence it is permissible to suggest that electric oscillations act by reestablishing in the nerve a contiguity which bad become insufficient. The same writer has recently shown that continuous currents of a sufficient electro-motive force produce in discontinuous conductors the same effects as discharges at a distance. It would be interesting, he suggests, to inquire if the mode of action of continuous currents in diseases of the nervous system where they have proved useful presents features similar to those which occur in discontinuous conductors. It is not claimed by $M$. Branly that anything more than a mere analogy has been shown, but the thinks it possible that such considerations may prove a useful guide in determining the modality in which electricity is to be employed in a given case, and perhaps furnish the electro-therapertist with a good working hypothesis.

So far it is evident that such speculations fall very far short of this. All that can be claimed is to have made out a case for further inquiry. Such a line of investigation has already been foreshadowed in an article by me whieh was published in THE LANCET, May 4th, 1895, and in which the following sentence occurs : "It seems even conceivable that other histological arrangements-e.g., those nerve fibrils which conduct yet only touch and do not anastomose, those motor nerve endings which are only in contact with the sarcous substance; indeed, any conducting aarrangement in the animal body which may be classed as a 'bad contact ' - may constitute the physiological analogue of what would be electrically known as "a coherer."

Hanşeld-street, W.

\section{Clinital a thotes:}

\section{MEDICAL, SURGICAL, OBSTETRICAL, AND} THERAPEUTICAL.

\section{NOTE ON A CASE OF HYDATID OF THE GALL BLADDER. \\ By Frederick Page, M.D. Edin., M.R.C.S. Eng.,}

SURGEON TO THE NEWCASTLE-UPON-TYNE ROTAL INEIRMARY.

EARLY last December a man between fifty and sixty years of age was sent to me for surgical treatment by Mr. Martin of Darlington with the following history. For the last five years the patient, who up to that time had always had excellent health, suffered from occasional attacks of pain in the epigastric region accompanied by vomiting - "bilious attacks," as he called them. Last summer these attacks became more severe and occurred more frequently. About 0ctober he began to lose flesh and the pain and vomiting were almost continuously present. On Nor. 24 th he was examined by Mr. Martin, who found a tumour of some size connected with the under surface of the liver which he took to be the dilated gall-bladder. He was sent to me early in December on Dec. 9th the abdomen was opened in the righ semilonar line and the gall-bladder was exposed. Some twelve ounces of clear colourless fluid were drawn off by aspiration and a stone searched for in the cystic duct. None was found and the gall-bladder was incised. Through the incision a collapsed hydatid cyst at once protruded. This was removed, but not in one piece. No bile escaped. The margin of the incision into the gall-bladder was then sutured to the skin and the abdominal wound was closed. For eleven days the temperature continued to be normal and all went well, a good deal of clear fluid escaping from the gallbladder quite unstained by bile. On the $23 \mathrm{rd}$ the temperature rose to $102^{\circ} \mathrm{F}$. and there was an unpleasant smell about the dressings. On examining the sinus into the gall-bladder its orifice was found to be plugged firmly by a piece of decomposed hydatid cyst, upon the removal of which a considerable quantity of bile escaped. From this time till the middle of February bile continued to flow, at first so copiously that it was necessary to change the saturated dressings twice and sometimes three times daily. On Jan. 12th the patient was allowed to return to his hom at Darlington very much improved and rapidly regaining his health and strength. The sinus closed in February. He is now quite well.

In this case the gall-bladder was occupied by a single hydatid cyst containing no daughter cysts. A portion of the cyst extending into the cystic duct had evidently not been removed at the time of operation. When this retained portion separated and became lodged in the sinus bile flowed Into and distended the gall-bladder, by this time considerably reduced in size, escaping through the sinus as soon as its plugged orifice was freed. Newcastle-upon-Tyne.

\section{DOUBLE PHLEGMASIA FOLLOWED BY GANGRENE} OF THE RIGHT FOOT.

By Thomas Fisher, M.R.C.S EvG., L.S.A., MEDICAL OFFICER OF HEALTH OF GARSTING.

A WOMAN, aged forty-four years, was confined of her fifteenth child on Nov. 26th, 1895. The confinement was very quick, the child being born on my arrival, but there was a retained placenta with severe post-partum hæmorrhage, the patient being in a very collapsed condition; there were great pallor, some delirium with dilated pupils, rapid breathing, and scarcely perceptible pulse. I dropped the head and raised the limbs, administered stimulants which were swallowed with difficulty, applied ammonia to the nostrils, and injected brandy subcutaneously. The condition of the patient was so serious that I did not deem it advisable to explore the uterus per vaginam until some restoration had taken place, but I simply directed $m y$ attention to external expression and injected ergotin. The effect of the treatment in about an hour's time was to restore the patient somewhat and I determined on removal of the placenta. Upon vaginal examination I found marked hourglass contraction of the uterus. After careful manipulation I removed the placenta, carefully following the contraction of the uterus with the left hand on the abdomen. The condition of the patient continued very grave, but there was no further hæmorrhage. Brandy and beaten egg-and-milk which were given were returned by the patient. Up to the third day the patient remained extremely exhausted, with a subnormal temperature and pulse. On the fourth day some tenderness of the abdomen was complained of and also some pain in the groins; there was offensive diarrhœe and the temperature was $103^{\circ} \mathrm{F}$. Up to the eighth day these symptoms continued and both limbs began to show the ordinary signs of phlegmasia, the right limb more markedly, it being very tense and shining with marked tenderness along the femoral and saphenous veins; the lymphatics were also very visibly irritated. The constitutional symptoms were those of marked "adynamia," the pulse being from 120 to 130 , with tongue dry and brown, thirst and some delirium, offensive diarrboea and lochial discharge, the temperature varying from $102^{\circ}$ to $104^{\circ}$ On the twelfth day the right limb presented several bullæe and there was distinct cedema, the foot below the ankle being of an ashen-red colour and the toes blue The general sensibility of the limb was lessened but more especially in the foot. Up to the twentieth day the condition of the patient was exceedingly grave, but nourishment and stimulants, with quinine, were freely taken and the offensive diarrhcea began to subside, the limb became less swollen, and there was an evident line of demarcation at the base of the toes. Both limbs during this period were elevated, wrapped in cotton wool and dressed with boracic powder. For the next thiee weeks the patient remained very weak gradually the symptoms of fever subsided, the offensive diarrhcea stopped, and the condition of the patient was much improved and more hopeful. I now decided on removal of the toes, the operation being successful and the wound healing well. The foot was still slightly odematous; this was in January, 1896. The patient was soon about on cratches and was in a short period of time able to attend to some of her household daties. In February, 1897, some tenderness and swelling appeared under the surface of the metatarsal bone of the big toe; this being opened up there was evident necrosis. Early in March with the assistance of Dr. G. Gibson this portion of diseased bone was successfully removed. In March, 1898 , the condition of the foot was still odematous, the blood-ressels 